\title{
CT Evaluation of Pelvic and Hip Fractures
}

\author{
Umesh Kumar Sharma, ${ }^{1}$ Anjali Basnyat, ${ }^{1}$ Keshab Rijal, ${ }^{1}$ Babu Kaji Shrestha, ${ }^{2}$ Bibek Banskota, ${ }^{2}$ Ashok Kumar \\ Banskota $^{2}$ \\ ${ }^{1}$ Department of Radiodiagnosis, ${ }^{2}$ Department of Orthopedics, B \& B teaching hospital, Gwarko, Lalitpur, Nepal.
}

\section{ABSTRACT}

Introduction: To analyze the spectrum of pelvic and hip joint injuries by computed tomography in patients attending to emergency.

Methods: CT evaluation with multiplanar and 3-D reformations of 62 patients done with pelvic and hip fractures during 18 months. The mode of injury and treatment were recorded.

Results: Forty four (70.9\%) of the injuries were sustained in high speed vehicle accidents (automobile, motorcycle, autopedestrian), 14 patients (22.5\%) had sustained fall injury and 4 patients $(6.4 \%)$ sustained injury following slip on the ground. 31 patients underwent surgery for acetabular fractures. Associated injuries included spinal fractures (5), abdominal visceral injury (3), extremity fractures (13), chest injury (5), head injury (1), urethral injury (4), clavicle fracture (1). Forty patients (64.5\%) had acetabular fractures, $25(40.3 \%)$ patients had iliac bone fractures, $47(75.8 \%)$ had pubic bone fracture. Sacral fracture was found in $17(27.4 \%)$ patients. Associated femoral fracture was found in 4, hip joint dislocation was seen in 5 (2-central, 3-posterior). Sacroiliac joint diastasis was found in $13(20.9 \%)$ patients, pubic diastasis in $7(11.2 \%)$, fracture ischium in $7(11 . \%)$, protrusio acetabuli in 5 $(8 \%)$.

Conclusions: Spiral CT with multiplanar and 3-D reformations has clinical values for precise diagnosis and treatment plan for the pelvic and hip fractures.

Keywords: pelvis; hip fractures; CT scan.

\section{INTRODUCTION}

Pelvic and hip bone fractures are common injuries encountered due to rising accidents particularly in the younger age group. ${ }^{1-3}$ Computed tomography (CT) is widely recognized as an important adjunct to plain films in the evaluation of patients with acute pelvic trauma, accurate diagnosis of orthopedic injuries and for further management. Patients sustaining injury to the hip due to high energy trauma should be evaluated promptly with plain radiographs and subsequent imaging by $\mathrm{CT}$ as the detailed fracture pattern may not be well appreciated on a plain radiograph in the stand $\mathrm{x}$-ray pelvis. Several authors have described the role of CT in pelvic fractures. ${ }^{1-12}$ Their results indicating error rates of $30-65 \%$ with plain films alone are not satisfying. ${ }^{12}$

\section{METHODS}

Sixty two patients who suffered trauma to the hip and pelvis were evaluated with computed tomography (CT) at B \& B hospital from January 2011 to July 2013.

Clinical informations and mode of injury were obtained

Correspondence: Dr. Umesh Kumar Sharma, Department of Radiodiagnosis, B\&B teaching hospital, Gwarku, Lalitpur, Nepal. Email: druksharma@hotmail.com, Phone: +977-9851071500. 
from the emergency department and details of the treatment were recorded. CT scan was performed on spiral CT (Siemens emotion) using $3 \mathrm{~mm}$ thick slices starting at the level of iliac crest with image interval space of $3 \mathrm{~mm}$; pitch of 1.5 to the inferior surface of the inferior pubic ramus. From October 2012 CT scan were performed using 16 slice CT scanner (Siemens emotion 16). Following CT, multiplanar reformation and 3D images were obtained.

Additional CT scan of the upper abdomen or other parts were performed as indicated.

\section{RESULTS}

A total of 62 patients were evaluated with CT scans for hip and pelvic bone fractures. Forty five men and 17 women were aged 15 months to 72 years, with mean age 31.4 years. $40(70.9 \%)$ of the injuries were sustained in high speed vehicle accidents (automobile, motorcycle, auto-pedestrian), 14 patients (16.1\%) had sustained fall injury and four patients $(6.4 \%)$ sustained injury following slip on the ground. Thirty one patients underwent surgery for acetabular fractures and one patient managed surgically for iliac and sacral bone fracture.

Forty patients $(64.5 \%)$ had acetabular fractures, 25 (40.3\%) patients had iliac bone fractures, 47 (75.8\%) had pubic bone fracture (superior ramus in 3 , inferior ramus in 19 , both superior and inferior rami in 15 , pubic body in 2, superior, inferior rami including body in eight (Figure 1-4). Sacral fracture was found in 17 (27.4\%) patients, of which two had both side involvement. Associated femoral fracture was found in four, hip joint dislocation was seen in five (2-central, 3-posterior) (Figure 3,6ab). Sacroiliac joint diastasis was found in $13(20.9 \%)$ patients, pubic diastasis in seven $(11.2 \%)$, fracture ischium in seven $(11 \%)$, protrusion acetabuli in five $(8 \%)$. B/L acetabular fractures were in three patients.

Out of 40 patients with acetabular fracture, the commonest fracture was both column in 12 patients $(30 \%)$ (Figure 1 ), seven $(17.5 \%)$ had anterior column (Figure 5$)$, seven $(17.5 \%)$ had T-shaped fracture (Figure $2)$, anterior wall fracture in four $(4 \%)$, posterior wall fracture in six $(15 \%)$, posterior column in two $(5 \%)$, posterior column with wall in one $(2.5 \%)$, transverse with posterior wall in one $(2.5 \%)$. Intraarticular fragments in the hip joint were present in four $(4 \%)$ patients (Figure 7).

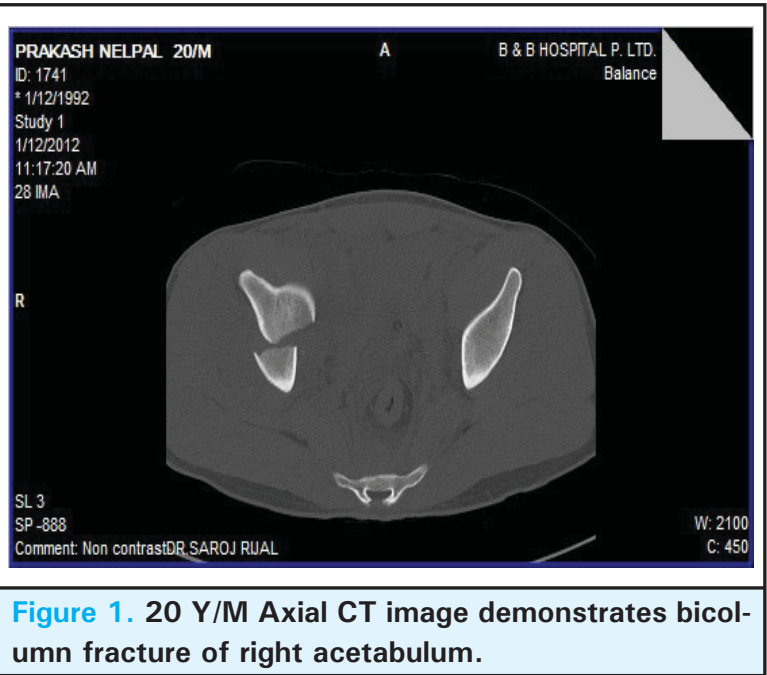

Associated injuries included spinal fractures (5), abdominal visceral injury (3), extremity fractures (13), chest injury (5), head injury (1), urethral injury (4), clavicle fracture (1).

The total number of injured pillion riders were eight, out of which five (62\%) had acetabular fractures. 14 patients had fall injury and eight $(57.1 \%)$ of them sustained acetabular fractures. Pubic bone fractures were common in these patients and found in seven pillion riders, and in nine patients with fall injury.

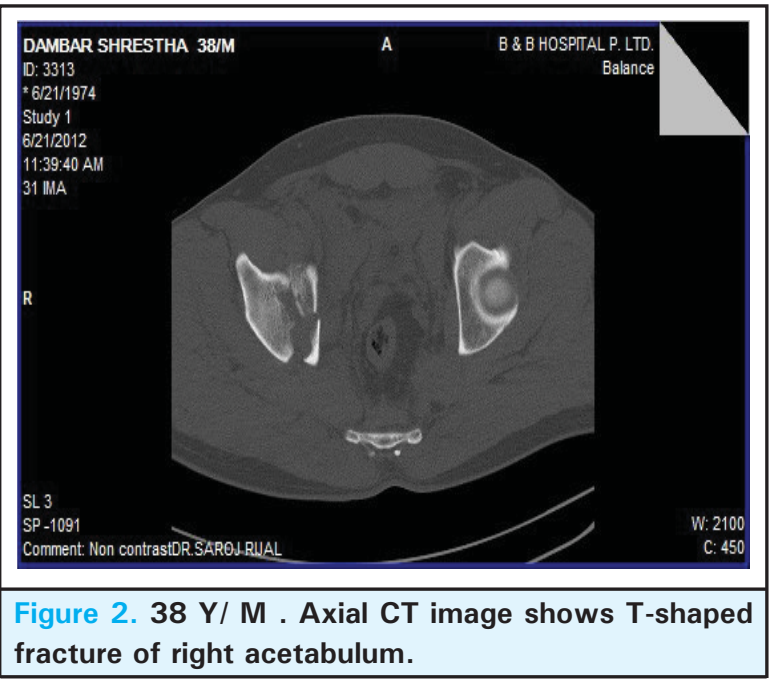




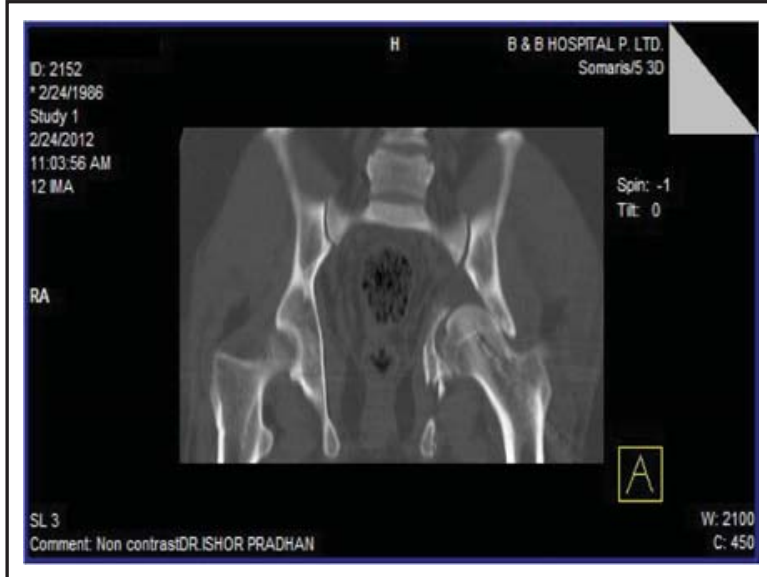

Figure 3. 26 Y/M. Multiplanar reformation image shows comminuted fracture of the left acetabulum with central dislocation.

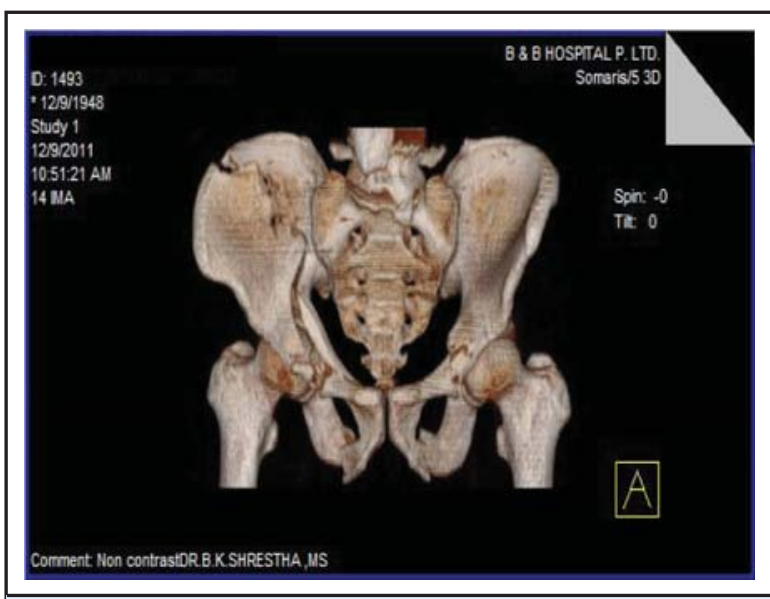

Figure 4. 3-D image of the pelvic ring fracture extending to the acetabulum on right side.

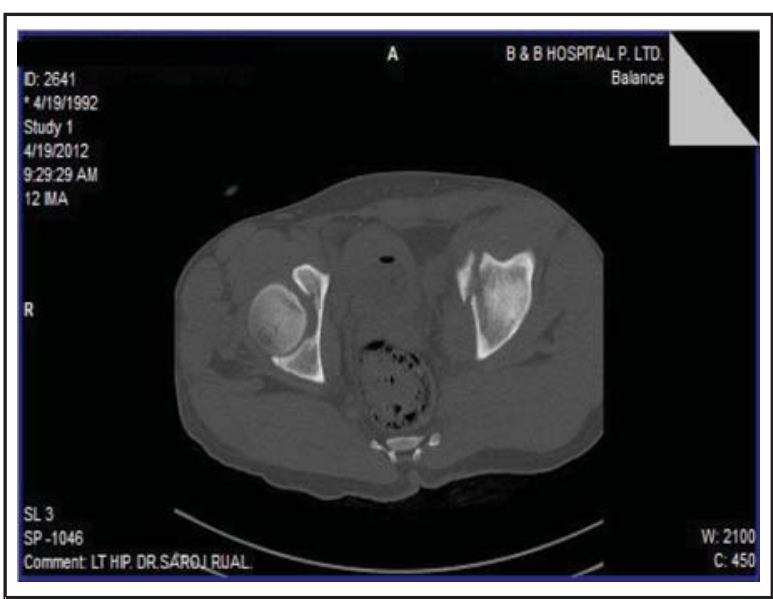

Figure 5. $20 \mathrm{Y} / \mathrm{M}$ with history of fall injury. Anterior column fracture of left acetabulum.
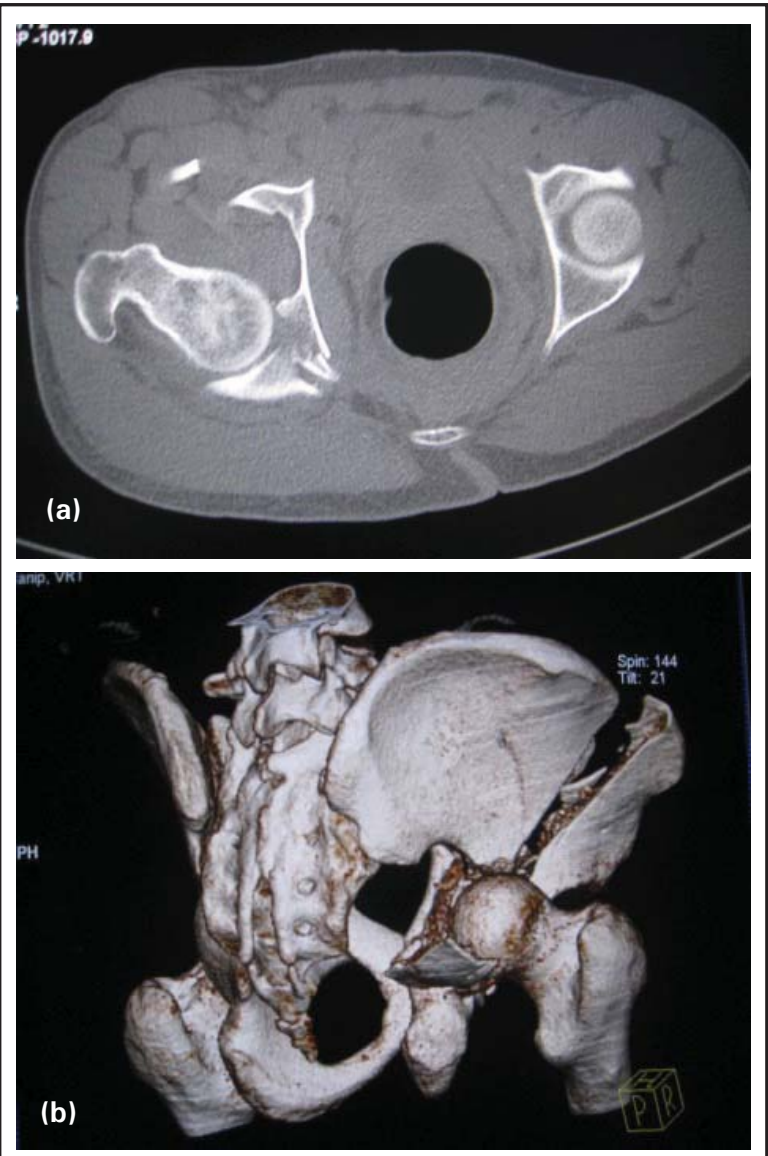

Figure 6. (a) $30 \mathrm{Y} / \mathrm{M}$ with history of motorbike accident. Axial and 3-D images of the pelvis shows displaced fracture of posterior wall of right acetabulum with posterior dislocation. (b) 3-D images demonstrates long segment iliac bone fracture and posterior dislocation of the hip joint.

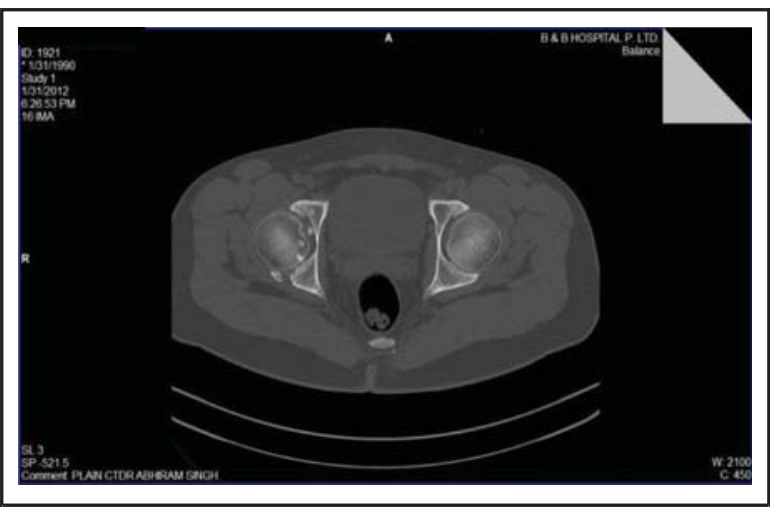

Figure 7.22Y/M: Axial CT image shows isolated posterior wall fracture of right acetabulum and intraarticular loose fragment. 


\section{DISCUSSION}

Several publications have documented a high frequency of missed pelvic fractures on plain films. ${ }^{1-3,8,10,12}$ Montana et al ${ }^{4}$ reported that 20 of 70 cases of diastasis of the sacroiliac joint were not detected on plain films. Analysis of the data and clinical history in this study revealed that trauma to the pelvic and acetabular fractures is seen more frequently in patients subjected to high energy trauma $(77.4 \%$ high energy group vs $22.5 \%$ low energy group).

CT is useful for examining patients with acetabular fractures. ${ }^{1,2,4,8,9}$ It detects intraarticular fragments and shows articular discontinuity better than radiography does. Rotation of fragments also can be difficult to assess by radiography and may be better examined with $\mathrm{CT}$. This information is useful for planning maneuvers to reduce the articular surface intraoperatively. The system developed by Judet et al and Letournel is a morphologic classification based on observations from radiography using anteroposterior and oblique radiographs (Judet views). ${ }^{14,15}$

Spiral CT combined with volume rendered multiplanar 2D and $3 \mathrm{D}$ reformatted images done in all patients reflecting its value in assessing the complex nature of pelvic and acetabular fractures (Figure 3,4,6b). These reformatted images provided easy interpretation of the overall assessment of the fracture patterns and complicated spatial information about the relative positions of fracture fragments can be easily demonstrated. Threedimensional reconstructions are helpful for surgical planning. These images are particularly helpful for surgeons or radiologists who are less experienced in the interpretation of the radiographs and even in the setting of more complex fracture patterns. ${ }^{15-17}$

The CT appearances of the fractures types of the Letournel and Judet classification have been described..$^{7-9,12-15}$ The prognosis in patients with fracture dislocations of the hip is greatly influenced by the treatment, which is based on the stability of the joint, congruity of fracture fragments, and the presence or absence of intraarticular loose fragments. ${ }^{5,6}$ Imaging by CT with or without the reformatted images gives the radiologist and the surgeon a proper understanding of the fracture pattern and thus valuable information in the choice of management - whether surgical or non-surgical. In our study $31(77.7 \%)$ patients with acetabular fractures underwent surgery, where as one patient with iliac and sacral bone fracture had been managed surgically. Rest of the pelvic fractures were managed conservatively.

Three patients had posterior dislocation of the hip, where as central dislocation was found in two, protrusio acetabuli in five. Total $32(51.6 \%)$ patients in the high energy group had fracture in other parts of the body or had blunt abdominal trauma, urethral or head injuries. Three patients had liver lacerations, three had urethral injury and one patient had head injury.

Both column acetabular fracture were most common as noted in the Harris classification (30\%). The fractures of anterior column and $\mathrm{T}$ shaped respectively occurred in $17.5 \%$ cases. Anterior column wall fracture occurred in $10 \%$, posterior wall in $15 \%$. Less common fracture were posterior column, (5\%), posterior column with wall $(2.5 \%)$, transverse with posterior wall $(2.5 \%)$.

Classifying acetabular fracture based on CT images according to Harris classification was found to be relatively less cumbersome than that of the $\mathrm{E}$. Brandshern classification ${ }^{15}$ which is based on the L-J classification, classifying the complex acetabular fractures into the 10 different categories were at times difficult and confusing as the fracture patterns can vary and may not fit into any of the groups.

Our results showed intraarticular fragments in $4 \%$ patients with acetabular fractures. Adam et $\mathrm{al}^{1}$ reported 10 intraarticular fragments in 30 patients with acetabular fractures, with only one diagnosed by using plain films. St Pierre et al ${ }^{18}$ described 20 such patients in 67 patients, none visible on plain films. Vas et al 19 detected none of 10 fragments in plain films. CT in these cases is vital to the planning of treatment and to the choice of surgical technique, because the presence of intraarticular fragments necessitates exploration of the hip joint. ${ }^{18}$

Fractures and dislocations about the hip are frequently associated with pelvic hematomas and other bony injuries to the pelvis. ${ }^{8}$ The CT scan can be displayed to give excellent soft-tissue visualization for localizing hematomas and can give some idea as to their size. The major disadvantage of CT scanning of the hip is the inability to visualize cartilaginous fragments. ${ }^{8}$

Our study showed sacral fractures in 17 patients. In a study by Hennes FO et al MRI performed better in the depiction of sacral fractures, reaching a sensitivity of $98.6 \%$ compared to $66.1 \%$ at CT. ${ }^{20}$

In our study CT scan precisely detected iliac bone fractures in 25 patients, which was useful for the surgical planning. Li FP et al found nine posterior and three anterior pelvic ring fractures were misdiagnosed according to plain radiographs, which were corrected by spiral CT examination. ${ }^{21}$ 


\section{CONCLUSIONS}

Pelvic and hip bone fractures are common injuries due to rising vehicle accidents particularly in the younger age group. Spiral CT with multiplanar reformations and 3-D reconstructions has clinical values for precise diagnosis and the treatment plan of complex hip and pelvic bone fractures.

\section{ACKNOWLEDGEMENTS}

Our sincere thanks to $\mathrm{Mr}$ Jhabindra Banjade and Mrs Salpa Shrestha who helped us in conducting the study.

\section{REFERENCES}

1. Adam P, Labbe JL, Alberge Y, Austry P, Delcroix P, Fict RP. The role of computed tomography in the assessment and treatment of acetabular fractures. Clin Radiol 1985;36:13-18.

2. Dunn EL, Berry PH, Connally JD. Computed tomography of the pelvis in patients with multiple injuries J Trauma 1983;23:378-383

3. Herley JD, Mack LA, Winquist RA. CT of acetabular fractures: Comparison with conventional radiography. AJR 1982; 138:413-417.

4. Montana MA, Richardson ML, Kilcoyne RF, Harley JD, Shuman WP, Mack LA. CT of sacral injury. Radiology 1986;161:499-503.

5. Epstein HC. Traumatic dislocations of the hip. Clin Othop 1973;92:116-142

6. Brav EA. Traumatic dislocation of the hip:army experience results over a twenty year period. J Bone Join Surg 1962;44:1115-1134

7. N Jarrod Durkee, Jon Jacobson, David Jamadar, Madhav A Karunakar, Yoav Morag, Curtis Hayes. Classification of common acetabular fractures: radiographic and CT appearances. AJR 2006;187:915-925.

8. Donald D Sauser, Phiroze E Billimoria, Glen A Rouse, Kenneth Mudge. CT evaluation of hip trauma. AJR 1980 135:269-274.

9. Laurence A. Mack, John D Harley, Robert A Winquist. CT of acetabular fractures: analysis of fracture patterns. AJR 1982;138:407-412.

10. Perez RM, Chana FR, Vaquero JM. Utility of 3D computed tomography for the surgical planning of pelvic fractures. Acta Ortop Mex 2010;24(5):306-11.

11. Li FP, Li M, Hua Q, Zha LJ, Lu JN. Study of the spiral CT reconstruction in the diagnosis and treatment of pelvic ring fractures. Zhongguo GU Shang 2010; 23(3): 204-7.
12. Charles SR, Daniel JS, Karthikamanathan S, Jeremy WR Young. Diagnosis of pelvic fractures in patients with acute pelvic trauma: Efficacy of plain radiographs. AJR 1992;158:109-112.

13. Martinez C, DiPasquale T, Helfet D,Graham A, Sanders R, Ray L. Evaluation of acetabular fractures with two and three dimension CT. Radiographics 1992;12:227-242.

14. Brandser EA, El-Khoury GY, Marsh JL. Acetabular fractures: a systematic approach to classification. Emerg Radiol $1995 ; 2: 18-28$

15. Eric Brandser, JL Marsh. Aceabular fractures:Easier classification with a systematic approach. AJR 1998;171:1217-28.

16. Fishman EK, Brebin B, Magid D et al. Volumetric rendering techniques: applications for three-dimensional imaging of the hip. Radiology 1987;163:737-738.

17. Scott WW, Fishman EK, Magid D, et al. Acetabular fractures:optimal imaging. Radiology 1987;165:537-539.

18. St. Pierre RK, Oliver T, Somoygi J, Whitesides T, Fleming LL. Computerized tomography in the evaluation and classification of fractures of the acetabulum. Clin Orthop 1984;188:234-237.

19. Vas WG, Wolverson MK, Sundaram M, et al. The role of computed tomography in pelvic fractures. J comput Assist Tomogr 1982;6:796-801.

20. Henes FO, Nuchtem JV, Groth M, Habermann CR, Regier $\mathrm{CR}$ et al. Comparison of diagnostic accuracy of Magnetic Resonance Imaging and Multidetector Computed Tomography in the detection of pelvic fractures. Eur J Radiol 2012;81(9):2337-42

21. Li FP, Li M, Hua Q, Zhao LJ, Luo JN. Study on the spiral CT reconstruction in the diagnosis and treatment of pelvic ring fractures. Zhongguo Gu Shang. 2010;23(3):204-7. 